\title{
Radiology
}

\section{Assessment of Brain Lesions in Type 2 Diabetes Mellitus and Hypertension using Magnetic Resonance Imaging}

\author{
Qurain Turki Alshammari ${ }^{1}$, Mohammed Salih ${ }^{1}$, Moawia Gameraddin ${ }^{2 *}$, Bushra \\ Abdelmalik $^{1}$, Sultan Alshoabi ${ }^{2}$, Elfadil Elnour ${ }^{1}$, Elgeili Yousif ${ }^{1}$ \\ ${ }^{1}$ Hail University, College of Medical Applied Sciences, Department of Diagnostic Radiology Sciences, \\ Hail, Saudi Arabia \\ ${ }^{2}$ Taibah University, Faculty of Applied Medical Sciences, Department of Diagnostic Radiologic Technology, \\ Al-Madinah, Saudi Arabia
}

\begin{abstract}
Background: Type 2 diabetes mellitus (T2DM) and hypertension (HTN) are risk factors for the spectrum of brain lesions. In this paper, we studied the impact of T2DM and HTN on the incidence of several brain lesions diagnosed with magnetic resonance imaging (MRI).

Methods and Results: This retrospective, single-center study was conducted at Royal Care International Hospital (Khartoum, Sudan) from January 2016 to December 2016 and included 80 patients (40 male and 40 female, aged between 20 years and 90 years) with suspected brain disorders. MRI brain examinations were conducted on a 1.5 Tesla MRI system (Toshiba Medical Systems, Tokyo, Japan). The following sequences were analyzed: T1-weighted imaging (T1WI), T2-weighted imaging (T2WI), fluid-attenuated inversion recovery (FLAIR), and diffusion-weighted imaging (DWI). Brain lesions were characterized by magnetic imaging spectroscopy and histopathological analysis. Binary logistic regression analysis was used to establish a mathematical model of the relationship between T2DM/HTN and the prevalence of brain lesions.

Among 80 patients, HTN, T2DM, and the combination of T2DM and HTN were identified in $18(22.5 \%), 9(11.2 \%)$, and $11(13.8 \%)$ patients, respectively. Brain lesions were found in $48(60 \%)$ patients and were most prevalent in the age group of 66-80 years. The brain lesions included ischemic brain infarction $(22.5 \%)$, brain tumors $(11.2 \%)$, cerebral hemorrhages $(6.2 \%)$, brain atrophy $(1.2 \%)$, ischemic brain infarction with brain atrophy $(16.2 \%)$, and brain metastases $(2.5 \%)$. Regression analysis showed that HTN and T2DM were associated with significantly higher ORs for brain lesions ([OR=2.459, 95\% CI: 1.673-3.614, $P<0.001]$ and $[\mathrm{OR}=1.507,95 \% \mathrm{CI}: 1.067-2.128, P=0.042]$, respectively). HTN was associated with significantly higher OR for ischemic brain infarction (OR=7.404, 95\% CI: $2.600-21.081, P<0.001)$.

Conclusion: The study showed a significant interaction between HTN and T2DM on the prevalence of brain lesions, especially ischemic brain infarction and brain atrophy.(International Journal of Biomedicine. 2020;10(4):382-386.)
\end{abstract}

Key Words: brain lesions $\bullet$ MRI $\bullet$ ischemic brain infarction $\bullet$ diabetes $\bullet$ hypertension

\section{Abbreviations}

BA, brain atrophy; CH, cerebral hemorrhages; DWI, diffusion-weighted imaging; FLAIR, fluid-attenuated inversion recovery; HTN, hypertension; IBI, ischemic brain infarction; MRI, magnetic resonance imaging; T2DM, type 2 diabetes mellitus.

\section{Introduction}

Type 2 diabetes mellitus (T2DM) and hypertension (HTN) are common risk factors associated with a spectrum of brain lesions such as ischemic brain infarcts (IBI), neurodegenerative outcomes, brain atrophy (BA), late-life cognitive impairment, and others. ${ }^{(1-4)}$
Magnetic resonance imaging (MRI) is widely used in diagnosing brain ischemic lesions, intracranial tumors, brain metastases, and other lesions. With recent advances in MRI technology, ischemic lesions can be identified with high accuracy using diffusion-weighted image $(88 \%-100 \%$ sensitivity and $95 \%-100 \%$ specificity)..$^{(5)}$ New diagnostic techniques, such as dynamic color mapping, diffusion-weighted imaging, diffusion 
tensor imaging, perfusion-weighted imaging, magnetic resonance spectroscopy, and functional MRI allow us to obtain detailed information about brain lesions. ${ }^{(6-8)}$

The aim of our study was to study the impact of T2DM and HTN on the incidence of several brain lesions diagnosed with MRI.

\section{Materials and Methods}

This retrospective, single-center study was conducted at Royal Care International Hospital (Khartoum, Sudan) from January 2016 to December 2016 and included 80 patients (40 male and 40 female, aged between 20 years and 90 years) with suspected brain disorders. Among 80 patients, HTN, T2DM, and the combination of T2DM and HTN were identified in $18(22.5 \%), 9(11.2 \%)$, and 11(13.8\%) patients, respectively.

HTN was diagnosed when a person's systolic blood pressure (SBP) was $\geq 140 \mathrm{mmHg}$ and/or their diastolic blood pressure (DBP) was $\geq 90 \mathrm{mmHg}$ following repeated examination. ${ }^{(9)}$ Diabetes was diagnosed when the patient has a fasting blood glucose level of $126 \mathrm{mg}$ per dL (7.0 mmol per L) or greater on two separate occasions. ${ }^{(10)}$

The data collection sheets completed for each subject included the following variables: sex, age, clinical history of HTN and T2DM, and MRI findings.

This study was approved by the ethics committee of the Royal Care International Hospital. Written informed consent was obtained from each patient.

MRI brain examinations were conducted on a 1.5 Tesla MRI system (Toshiba Medical Systems, Tokyo, Japan). Each patient was scanned supine on the examination couch with his or her head within the head coil. Images were obtained in a plane orthogonal to the long axis of the hippocampus; this plane is orientated parallel to the brainstem. The following sequences (slice thickness/interslice distance of $5 \mathrm{~mm} / 1.5 \mathrm{~mm}$ ) were analyzed: T1-weighted imaging (T1WI), T2-weighted imaging (T2WI), fluid-attenuated inversion recovery (FLAIR), and diffusion-weighted imaging (DWI). Brain lesions were characterized by magnetic imaging spectroscopy and histopathological analysis.

Statistical analysis was performed using IBM SPSS Statistics 23. Binary logistic regression analysis was used to establish a mathematical model of the relationship between T2DM/HTN and the prevalence of brain lesions. Odd ratios (OR) and their 95\% confidence intervals $(95 \% \mathrm{CI})$ were calculated. A probability value of $P<0.05$ was considered statistically significant.

\section{Results and Discussion}

The demographic, clinical characteristics and medical history of study participants are presented in Table 1. Among 80 patients, HTN, T2DM, and the combination of T2DM and HTN were identified in $18(22.5 \%), 9(11.2 \%)$, and $11(13.8 \%)$ patients, respectively. Brain lesions were identified in $48(60 \%)$ patients (Table 1) and were most prevalent in the age group of 66-80 years. The brain lesions included ischemic brain infarction (IBI) $(22.5 \%)$, brain tumors $(11.2 \%)$, cerebral hemorrhages $(\mathrm{CH})$
(6.2\%), brain atrophy (BA) $(1.2 \%)$, IBI with BA (16.2\%), and brain metastases $(2.5 \%)$. IBI with and without BA was found in $16.2 \%$ and $22.5 \%$ cases, respectively, (Fig. 1 and Table 2) and accounted for $27.1 \%$ and $37.5 \%$, respectively, of all brain lesions. Brain tumors accounted for $18.8 \%$ of all brain lesions, whereas cerebral hemorrhage for $10.4 \%$. The other brain lesions were less frequent. IBI was most common in the age groups of 51-65 and 66-80, whereas IBI and BA were most frequent in the age group of 66-80 years (Table 2). The prevalence of brain tumors was most frequently found in the age group of 36-50 years. Figure 2 shows the distribution of brain lesions between males and females. It was observed that IBI and IBI+BA were higher among males than among females (10 vs. 8 and 9 vs. 4 , respectively). It was found that $\mathrm{IBI}+\mathrm{BA}$ was prevalent $(63.6 \%)$ in patients with T2DM and HTN (Table 3).

Table 1:

The demographic, clinical characteristics and medical history of study participants

\begin{tabular}{|l|c|c|}
\hline \multicolumn{1}{|c|}{ Variable } & \multicolumn{1}{|c|}{$\begin{array}{c}\text { Absolute } \\
\text { number }\end{array}$} & Percent, \% \\
\hline Males & 40 & 50 \\
\hline Females & 40 & 50 \\
\hline Age groups & 19 & 16.7 \\
\hline 20-35 years & 18 & 15.8 \\
\hline 36-50 years & 16 & 14.0 \\
\hline 51-65 years & 23 & 20.2 \\
\hline 66-80 years & 4 & 3.5 \\
\hline $81-90$ years & 42 & 52.5 \\
\hline Clinical history & 9 & 11.2 \\
\hline None & 18 & 22.5 \\
\hline T2DM & 11 & 13.8 \\
\hline HTN & & \\
\hline T2DM+HTN & 48 & 60.0 \\
\hline $\begin{array}{l}\text { MRI Diagnosis of } \\
\text { brain lesions }\end{array}$ & 32 & 40.0 \\
\hline Yes & & \\
\hline No & & \\
\hline
\end{tabular}

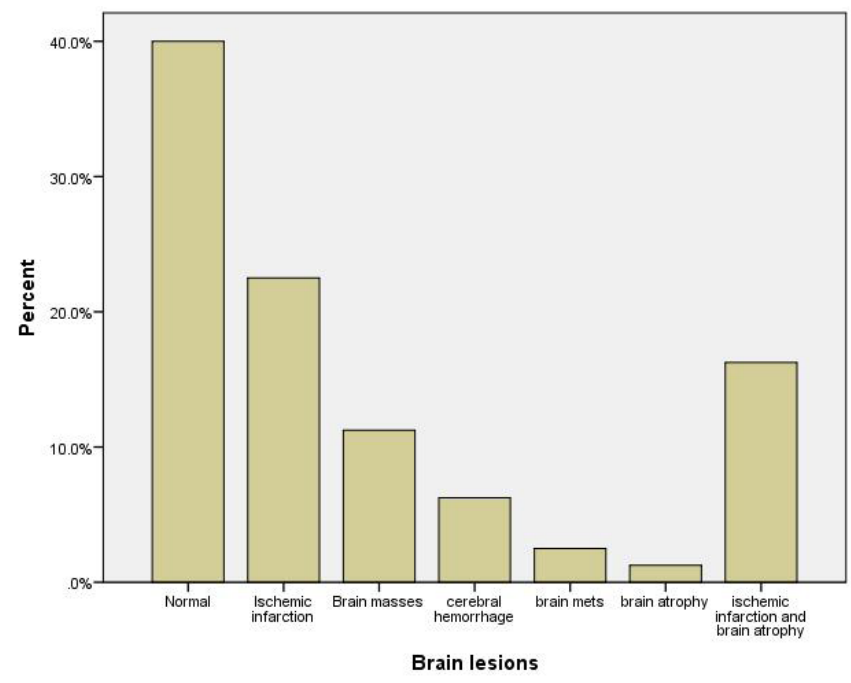

Fig. 1. Distribution of spectrum brain lesions in the study sample. 
Table2.

Incidence of brain lesions in different age groups

\begin{tabular}{|c|c|c|c|c|c|c|c|}
\hline $\begin{array}{l}\text { Age } \\
\text { groups }\end{array}$ & $\begin{array}{c}\text { No brain } \\
\text { lesions }\end{array}$ & IBI & $\begin{array}{l}\text { Brain } \\
\text { tumors }\end{array}$ & $\mathrm{CH}$ & $\begin{array}{l}\text { Brain } \\
\text { Mets }\end{array}$ & BA & $\begin{array}{c}\text { IBI } \\
\text { and BA }\end{array}$ \\
\hline & (78.9 & $\begin{array}{c}2 \\
(10.5 \%)\end{array}$ & $\begin{array}{c}1 \\
(5.3 \%)\end{array}$ & 1 & - & & - \\
\hline & $\begin{array}{c}12 \\
(66.7 \%)\end{array}$ & $\begin{array}{c}2 \\
(11.1 \%)\end{array}$ & $\begin{array}{c}4 \\
(22.2 \%)\end{array}$ & - & - & - & - \\
\hline $\begin{array}{l}51- \\
(\mathrm{n}=\end{array}$ & $\begin{array}{c}3 \\
(18.8 \%)\end{array}$ & $\begin{array}{c}8 \\
(50.0 \%)\end{array}$ & $\begin{array}{c}1 \\
(6.2 \%)\end{array}$ & $\begin{array}{c}1 \\
(6.2 \%)\end{array}$ & $\begin{array}{c}2 \\
\left(12.5^{\circ}\right.\end{array}$ & - & $\begin{array}{c}1 \\
(6.2 \%)\end{array}$ \\
\hline $\begin{array}{l}66-80 \text { yrs } \\
(\mathrm{n}=23)\end{array}$ & $\begin{array}{c}2 \\
(8.7 \%)\end{array}$ & $\begin{array}{c}6 \\
(26.1 \%)\end{array}$ & $\begin{array}{c}3 \\
(13.0 \%)\end{array}$ & $\begin{array}{c}3 \\
(13.0 \%)\end{array}$ & - & $\begin{array}{c}1 \\
(4.3 \%)\end{array}$ & $\begin{array}{c}8 \\
(34.8 \%)\end{array}$ \\
\hline 81 & - & - & - & - & -- & - & $\begin{array}{c}4 \\
(100 \%)\end{array}$ \\
\hline $\begin{array}{l}\text { Total } \\
(\mathrm{n}=80)\end{array}$ & $\begin{array}{c}32 \\
(40.0 \%)\end{array}$ & $\begin{array}{c}18 \\
(22.5 \%)\end{array}$ & $\begin{array}{c}9 \\
(11.2 \%)\end{array}$ & $\begin{array}{c}5 \\
(6.2 \%)\end{array}$ & $\begin{array}{c}2 \\
(2.5 \%)\end{array}$ & $\begin{array}{c}1 \\
(1.2 \%\end{array}$ & $\begin{array}{c}13 \\
(16.2 \%)\end{array}$ \\
\hline
\end{tabular}

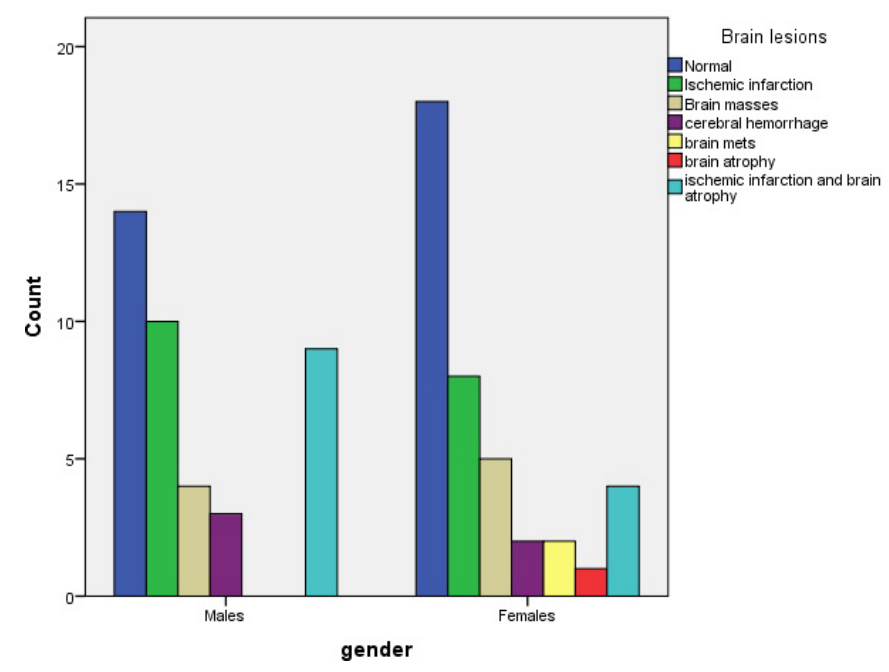

Fig. 2. Distribution of brain lesions according to gender

Table 3.

Brain lesions in the study participants

\begin{tabular}{|c|c|c|c|c|c|c|c|}
\hline \multirow{2}{*}{$\begin{array}{l}\text { Clinical } \\
\text { history }\end{array}$} & \multicolumn{7}{|c|}{ Brain lesions } \\
\hline & $\begin{array}{l}\text { No brain } \\
\text { lesions }\end{array}$ & IBI & $\begin{array}{l}\text { Brain } \\
\text { tumors }\end{array}$ & $\mathrm{CH}$ & $\begin{array}{l}\text { Brain } \\
\text { Mets }\end{array}$ & BA & $\begin{array}{c}\text { IBI } \\
\text { and BA }\end{array}$ \\
\hline $\begin{array}{l}\text { No history } \\
\text { of T2DM } \\
\text { and HTN }\end{array}$ & $\begin{array}{c}25 \\
(59.5 \%)\end{array}$ & $\begin{array}{c}7 \\
(16.7 \%)\end{array}$ & $\begin{array}{c}5 \\
(11.9 \%)\end{array}$ & $\begin{array}{c}1 \\
(2.4 \%)\end{array}$ & $\begin{array}{c}2 \\
(4.8 \%)\end{array}$ & - & $\mid \begin{array}{c}2 \\
(4.8 \%)\end{array}$ \\
\hline $\begin{array}{l}\text { T2DM } \\
(\mathrm{n}=9)\end{array}$ & $\begin{array}{c}4 \\
(44.4 \%)\end{array}$ & $\begin{array}{c}3 \\
(33.3 \%)\end{array}$ & $\mid \begin{array}{c}1 \\
(11.1 \%)\end{array}$ & $\begin{array}{c}1 \\
(11.1 \%)\end{array}$ & - & - & - \\
\hline $\begin{array}{l}\mathrm{HTN} \\
(\mathrm{n}=18)\end{array}$ & $\begin{array}{c}2 \\
(11.1 \%)\end{array}$ & $\begin{array}{c}7 \\
(38.9 \%)\end{array}$ & $\begin{array}{c}2 \\
(11.1 \%)\end{array}$ & $\begin{array}{c}2 \\
(11.1 \%\end{array}$ & - & $\begin{array}{c}1 \\
(5.6 \%)\end{array}$ & $\begin{array}{c}4 \\
(22.2 \%) \\
\end{array}$ \\
\hline $\begin{array}{l}\text { T2DM } \\
\text { and } \\
\text { HTN } \\
(\mathrm{n}=11)\end{array}$ & $\begin{array}{c}1 \\
(9.1 \%)\end{array}$ & $\begin{array}{c}1 \\
(9.1 \%)\end{array}$ & $\left(\begin{array}{c}1 \\
(9.1 \%)\end{array}\right.$ & $\begin{array}{c}1 \\
(9.1 \%)\end{array}$ & - & - & $\mid \begin{array}{c}7 \\
(63.6 \%)\end{array}$ \\
\hline $\begin{array}{l}\text { Total } \\
(\mathrm{n}=80)\end{array}$ & $\begin{array}{c}32 \\
(40.0 \%)\end{array}$ & $\begin{array}{c}18 \\
(22.5 \%)\end{array}$ & $\left(\begin{array}{c}9 \\
(11.2 \%)\end{array}\right.$ & $\begin{array}{c}5 \\
(6.2 \%)\end{array}$ & $\begin{array}{c}2 \\
(2.5 \%)\end{array}$ & $\begin{array}{c}1 \\
(1.2 \%)\end{array}$ & $\begin{array}{c}13 \\
(16.2 \%)\end{array}$ \\
\hline
\end{tabular}

T2DM was associated with a significantly higher OR for cerebral hemorrhage, although the relationship was statistically insignificant $(P=0.22)$ (Fig.3). The associations between brain tumors and T2DM or HTN were of no significance $(P>0.05)$ (Fig.4).

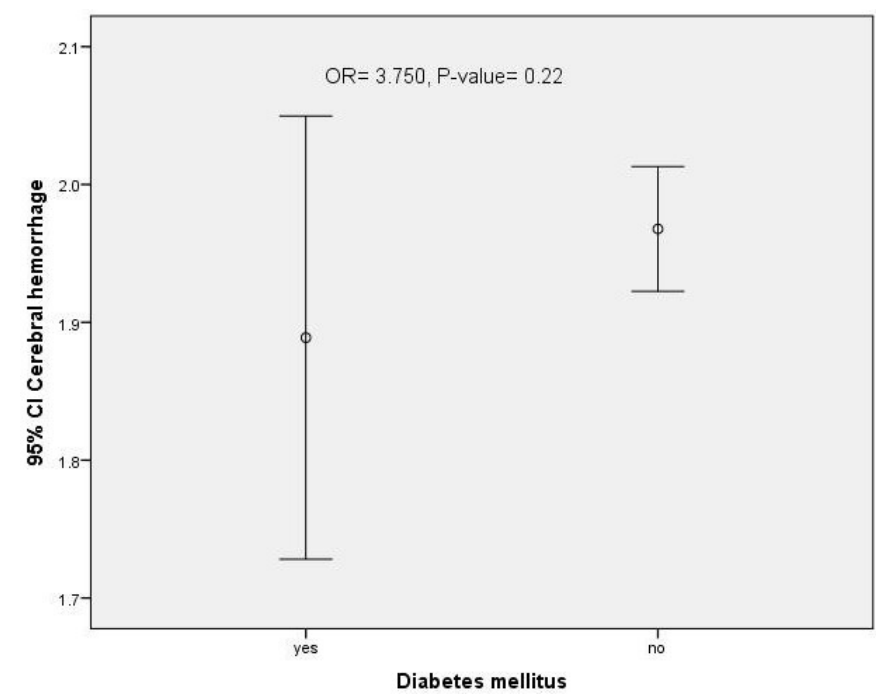

Fig. 3. Association of T2DM with cerebral hemorrhages

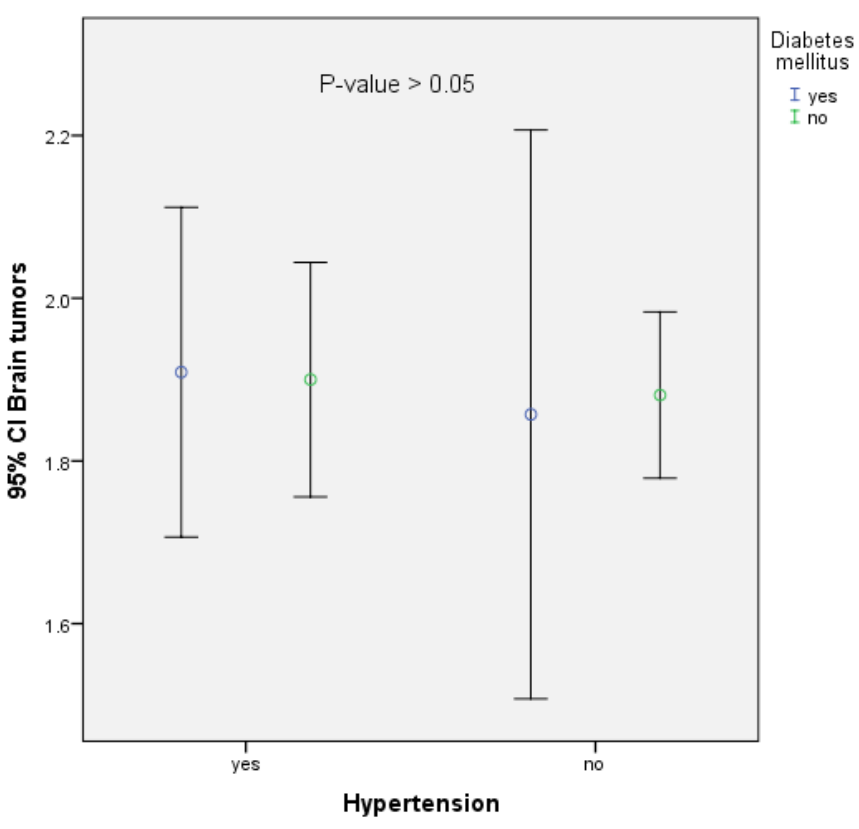

Fig. 4. Association of T2DM and HTN with brain tumours

Regression analysis showed that HTN and T2DM were associated with significantly higher ORs for brain lesions ([OR=2.459, 95\% CI: 1.673-3.614, $P<0.001], \quad[\mathrm{OR}=1.507$, 95\% CI: 1.067-2.128, $P=0.042]$ (Table 4). Table 5 summarizes the associated factors of ischemic brain infarction. HTN was associated with significantly higher OR for ischemic brain infarction $(\mathrm{OR}=7.404,95 \% \mathrm{CI}$ : 2.600-21.081, $P<0.001)$, while the associations between the risk of ischemic brain infarction and sex or diabetes were of no significance.

T2DM and HTN are potent risk factors for cerebrovascular disease. Brain ischemic lesions are frequently seen on brain MRI especially in the elderly population. Hypertension and 
T2DM were reported to be strongly associated with risks of vascular brain lesions, neurodegeneration, IBI, and BA. ${ }^{(11-15)}$ The evidence for the relation between blood pressure and brain atrophy is less clear. ${ }^{(12)}$ Some studies showing that high midlife blood pressure is related to BA later in life, ${ }^{(16-18)}$ while others show that in older individuals, especially low blood pressure levels lead to an increased risk for BA..$^{(19,20)}$

\section{Table 4.}

Binary logistic regression analysis of associated factors for brain lesions

\begin{tabular}{|l|c|c|c|c|c|c|}
\hline Variable & B & SE & $\chi^{2}$ & Sig. & OR & $95 \%$ CI \\
\hline Gender & -0.077 & 0.635 & 0.015 & 0.904 & 0.926 & $0.267-3.216$ \\
\hline Age & 0.075 & 0.022 & 12.160 & 0.001 & 1.078 & $1.033-1.124$ \\
\hline HTN & -1.565 & 0.802 & 22.312 & $<001$ & 2.459 & $1.673-3.614$ \\
\hline T2DM & 0.109 & 0.839 & 3.908 & 0.042 & 1.507 & $1.067-2.128$ \\
\hline
\end{tabular}

Table 5.

Binary logistic regression analysis of associated factors for brain ischemic infarction

\begin{tabular}{|l|c|c|c|c|c|c|}
\hline Variable & B & SE & $\chi^{2}$ & Sig. & OR & $95 \%$ CI \\
\hline Gender & 0.494 & 0.601 & 0.675 & 0.411 & 1.639 & $0.504-5.327$ \\
\hline Age & -0.065 & 0.021 & 9.457 & 0.002 & 0.937 & $0.900-0.977$ \\
\hline HTN & 2.002 & 0.534 & 14.060 & $<0.001$ & 7.404 & $2.600-21.081$ \\
\hline T2DM & 1.032 & 0.634 & 2.646 & 0.104 & 2.806 & $0.810-9.723$ \\
\hline
\end{tabular}

The current study supports the hypothesis that T2DM and HTN increased the risk of various brain lesions. IBI and BA were the most prevalent lesions in the study sample with HTN and T2DM. Our results are in agreement with the data obtained by Roberts et al. ${ }^{(21)}$ Moran et al. reported that T2DM was associated with more cerebral infarcts and lower total gray, white, and hippocampal volumes. ${ }^{(22)}$

The mechanisms by which T2DM and HTN cause brain lesions are disputed. They may primarily target blood vessel structure and function to cause vascular damage or may interact at the cellular level with neurons or synapses that affect neurodegenerative processes and promote brain neurodegeneration. ${ }^{(21,23,24)}$

As we age, structural changes occur throughout the brain. Such common brain changes include global atrophy, white matter injury, small-vessel ischemia, and microhemorrhages. (25-29) These changes are more frequent and more severe in HTN and T2DM. The present study revealed that the incidence of brain lesions, especially brain atrophy, increased with age. Our results are consistent with T. Gu et al. ${ }^{(30)}$ who found that age and the number of cardiovascular risk factors are independently associated with the brain atrophy and lesion index score.

Accumulating evidence suggests that a history of diabetes may be involved in the occurrence of various types of cancer. ${ }^{(31-34)}$ The findings of the meta-analysis performed by Tong et al ${ }^{(35)}$ indicate that diabetic individuals have a similar risk of brain tumors as non-diabetic individuals. However, a significant positive correlation between the risk of brain tumors and diabetes mellitus was revealed in females, but not in males. Our study found that DM and HTN were not significantly associated with the incidence rates for brain tumors.

In conclusion, HTN and T2DM are associated with advanced brain damage. The current study showed a significant interaction between HTN and T2DM on the prevalence of brain lesions, especially ischemic brain infarcts and brain atrophy.

\section{Competing Interests}

The authors declare that they have no competing interests.

\section{Acknowledgments}

We would like to thank all the radiologists and technologists at Royal Care International Hospital(RCIH) Khartoum for their assistance in this study.

\section{References}

1. Beeri MS, Silverman JM, Davis KL, et al. Type 2 diabetes is negatively associated with Alzheimer's disease neuropathology. J Gerontol A Biol Sci Med Sci. 2005;60(4):471-475. doi:10.1093/gerona/60.4.471

2. Arvanitakis Z, Schneider JA, Wilson RS, et al. Diabetes is related to cerebral infarction but not to AD pathology in older persons. Neurology. 2006;67(11):1960-1965. doi:10.1212/01. wnl.0000247053.45483.4e

3. Sonnen JA, Larson EB, Brickell K, et al. Different patterns of cerebral injury in dementia with or without diabetes. Arch Neurol. 2009;66(3):315-322. doi:10.1001/ archneurol.2008.579

4. Zimering MB, Patel D, Bahn G. Type 2 Diabetes Predicts Increased Risk of Neurodegenerative Complications in Veterans Suffering Traumatic Brain Injury. J Endocrinol Diabetes. 2019;6(3):137. doi:10.15226/2374-6890/6/3/001137 5. Provost C, Soudant M, Legrand L, et al. Magnetic Resonance Imaging or Computed Tomography Before Treatment in Acute Ischemic Stroke. Stroke. 2019;50(3):659664. doi:10.1161/STROKEAHA.118.023882

6. Karnath HO, Sperber C, Rorden C. Mapping human brain lesions and their functional consequences. Neuroimage. 2018;165:180-189. doi:10.1016/j.neuroimage.2017.10.028

7. Mehrabian H, Detsky J, Soliman H, Sahgal A, Stanisz GJ. Advanced Magnetic Resonance Imaging Techniques in Management of Brain Metastases. Front Oncol. 2019;9:440. Published 2019 Jun 4. doi:10.3389/fonc.2019.00440

8. Zhu H, Barker PB. MR spectroscopy and spectroscopic imaging of the brain. Methods Mol Biol. 2011;711:203-226. doi:10.1007/978-1-61737-992-5_9

*Corresponding author: Associate professor Moawia Gameraddin, Department of Diagnostic Radiologic Technology, Faculty of Applied Medical Sciences, Taibah University, Al-Madinah Al-Munawarah, Saudi Arabia.Email: gameradinm@gmail.com 
9. Unger T, Borghi C, Charchar F, et al. 2020 International Society of Hypertension global hypertension practice guidelines. J Hypertens. 2020;38(6):982-1004. doi:10.1097/ HJH.0000000000002453

10. Liberopoulos EN, Florentin M, Kei A, Mountzouri E, Agouridis A, Elisaf MS. Comparison of hemoglobin A1c and fasting glucose criteria to diagnose diabetes among people with metabolic syndrome and fasting glucose above $100 \mathrm{mg} / \mathrm{dL}$ (5.5 mmol/L). J Clin Hypertens (Greenwich). 2010;12(7):543548. doi:10.1111/j.1751-7176.2010.00318.x

11. Nation DA, Edmonds EC, Bangen KJ, et al. Pulse pressure in relation to tau-mediated neurodegeneration, cerebral amyloidosis, and progression to dementia in very old adults. JAMA Neurol. 2015;72(5):546-553. doi:10.1001/ jamaneurol.2014.4477

12. Jochemsen HM, Muller M, Visseren FL, et al. Blood pressure and progression of brain atrophy: the SMART-MR Study. JAMA Neurol. 2013;70(8):1046-1053. doi:10.1001/ jamaneurol.2013.217

13. de Leeuw FE, de Groot JC, Oudkerk M, et al. Hypertension and cerebral white matter lesions in a prospective cohort study. Brain. 2002;125(Pt 4):765-772. doi:10.1093/brain/ awf077

14. Debette S, Seshadri S, Beiser A, et al. Midlife vascular risk factor exposure accelerates structural brain aging and cognitive decline. Neurology. 2011;77(5):461-468. doi:10.1212/WNL.0b013e318227b227

15. Launer LJ. Epidemiology of white matter lesions. Top Magn Reson Imaging. 2004;15(6):365-367. doi:10.1097/01. rmr.0000168216.98338.8d

16. DeCarli C, Miller BL, Swan GE, et al. Predictors of brain morphology for the men of the NHLBI twin study. Stroke. 1999;30(3):529-536. doi:10.1161/01.str.30.3.529

17. Korf ES, White LR, Scheltens P, Launer LJ. Midlife blood pressure and the risk of hippocampal atrophy: the Honolulu Asia Aging Study. Hypertension. 2004;44(1):29-34. doi:10.1161/01.HYP.0000132475.32317.bb

18. Swan GE, DeCarli C, Miller BL, et al. Association of midlife blood pressure to late-life cognitive decline and brain morphology. Neurology. 1998;51(4):986-993. doi:10.1212/ wnl.51.4.986

19. den Heijer T, Launer LJ, Prins ND, et al. Association between blood pressure, white matter lesions, and atrophy of the medial temporal lobe. Neurology. 2005;64(2):263-267. doi:10.1212/01.WNL.0000149641.55751.2E

20. Skoog I, Andreasson LA, Landahl S, Lernfelt B. A population-based study on blood pressure and brain atrophy in 85-year-olds. Hypertension. 1998;32(3):404-409. doi:10.1161/01.hyp.32.3.404

21. Roberts RO, Knopman DS, Przybelski SA, et al. Association of type 2 diabetes with brain atrophy and cognitive impairment. Neurology. 2014;82(13):1132-1141. doi:10.1212/WNL.0000000000000269

22. Moran C, Phan TG, Chen J, et al. Brain atrophy in type 2 diabetes: regional distribution and influence on cognition. Diabetes Care. 2013;36(12):4036-4042. doi:10.2337/dc13-0143

23. Zeger M, Popken G, Zhang J, et al. Insulin-like growth factor type 1 receptor signaling in the cells of oligodendrocyte lineage is required for normal in vivo oligodendrocyte development and myelination. Glia. 2007;55(4):400-411. doi:10.1002/glia.20469

24. Freude S, Schilbach K, Schubert M. The role of IGF-1 receptor and insulin receptor signaling for the pathogenesis of Alzheimer's disease: from model organisms to human disease. Curr Alzheimer Res. 2009;6(3):213-223. doi:10.2174/156720509788486527

25. Guo H, Song X, Vandorpe R, et al. Evaluation of common structural brain changes in aging and Alzheimer disease with the use of an MRI-based brain atrophy and lesion index: a comparison between T1WI and T2WI at 1.5T and 3T. AJNR Am J Neuroradiol. 2014;35(3):504-512. doi:10.3174/ajnr.A3709

26. Jagust WJ, Zheng L, Harvey DJ, et al. Neuropathological basis of magnetic resonance images in aging and dementia. Ann Neurol. 2008;63(1):72-80. doi:10.1002/ana.21296

27. Kim KW, MacFall JR, Payne ME. Classification of white matter lesions on magnetic resonance imaging in elderly persons. Biol Psychiatry. 2008;64(4):273-280. doi:10.1016/j. biopsych.2008.03.024

28. Lane CA, Barnes J, Nicholas JM, et al. Associations Between Vascular Risk Across Adulthood and Brain Pathology in Late Life: Evidence From a British Birth Cohort. JAMA Neurol. 2020;77(2):175-183. doi:10.1001/ jamaneurol.2019.3774

29. Bos D, Poels MM, Adams HH, et al. Prevalence, Clinical Management, and Natural Course of Incidental Findings on Brain MR Images: The Population-based Rotterdam Scan Study. Radiology. 2016;281(2):507-515. doi:10.1148/ radiol.2016160218

30. Gu T, Fu C, Shen Z, et al. Age-Related Whole-Brain Structural Changes in Relation to Cardiovascular Risks Across the Adult Age Spectrum. Front Aging Neurosci. 2019;11:85. Published 2019 Apr 24. doi:10.3389/fnagi.2019.00085

31. Heidemann C, Boeing H, Pischon T, Nöthlings U, Joost HG, Schulze MB. Association of a diabetes risk score with risk of myocardial infarction, stroke, specific types of cancer, and mortality: a prospective study in the European Prospective Investigation into Cancer and Nutrition (EPIC)-Potsdam cohort. Eur J Epidemiol. 2009;24(6):281-288. doi:10.1007/ s10654-009-9338-7

32. Saltzman BS, Doherty JA, Hill DA, et al. Diabetes and endometrial cancer: an evaluation of the modifying effects of other known risk factors. Am J Epidemiol. 2008;167(5):607614. doi:10.1093/aje/kwm333

33. Ben Q, Cai Q, Li Z, et al. The relationship between new-onset diabetes mellitus and pancreatic cancer risk: a case-control study. Eur J Cancer. 2011;47(2):248-254. doi:10.1016/j.ejca.2010.07.010

34. Wang CS, Yao WJ, Chang TT, Wang ST, Chou P. The impact of type 2 diabetes on the development of hepatocellular carcinoma in different viral hepatitis statuses. Cancer Epidemiol Biomarkers Prev. 2009;18(7):2054-2060. doi:10.1158/1055-9965.EPI-08-1131

35. Tong JJ, Tao H, Hui OT, Jian C. Diabetes mellitus and risk of brain tumors: A meta-analysis. Exp Ther Med. 2012;4(5):877-882. doi:10.3892/etm.2012.698 